\title{
Characterization of salt consumption among hypertensives according to socio-demographic and clinical factors ${ }^{1}$
}

\author{
Milena Sia Perin ${ }^{2}$ \\ Marilia Estevam Cornélio ${ }^{3}$ \\ Roberta Cunha Matheus Rodrigues ${ }^{4}$ \\ Maria Cecilia Bueno Jayme Gallani ${ }^{5}$
}

\begin{abstract}
Objective: to evaluate the relationship between the behaviors of salt consumption and sociodemographic and clinical variables. Method: sodium consumption was evaluated using the methods: self-reporting (considering 3 different behaviors related to salt consumption), 24hr dietary recall, discretionary salt, food frequency questionnaire, estimation of total sodium intake and 24-hr urinary excretion of sodium $(n=108)$. Results: elevated salt intake according to the different measurements of consumption of the nutrient was associated with the variables: male sex, low level of schooling and monthly income, being Caucasian, and being professionally inactive; and with the clinical variables: elevated Body Mass Index, tensional levels, ventricular hypertrophy and the number of medications used. Conclusion: the data obtained shows a heterogenous association between the different behaviors related to salt consumption and the socio-demographic and clinical variables. This data can be used to optimize the directing of educational activities with a view to reducing salt consumption among hypertensives.
\end{abstract}

Descriptors: Nursing; Sodium Chloride, Dietary; Hypertension; Feeding Behavior; Sex; Social Class.

\footnotetext{
${ }^{1}$ Supported by Fundação de Amparo à Pesquisa do Estado de São Paulo (FAPESP), process \# 2009/14461-4.

2 Undergraduate student in Nursing, Faculdade de Enfermagem, Universidade Estadual de Campinas, Campinas, SP, Brazil.

${ }^{3}$ Doctoral student, Faculdade de Enfermagem, Universidade Estadual de Campinas, Campinas, SP, Brazil.

${ }^{4} \mathrm{PhD}$, Associate Professor, Faculdade de Enfermagem, Universidade Estadual de Campinas, Campinas, SP, Brazil.

${ }^{5}$ PhD, Associate Professor, Faculdade de Enfermagem, Universidade Estadual de Campinas, Campinas, SP, Brazil. Full Professor, Faculté des sciences infirmières, Université Laval, Québec, Canada.
}

\footnotetext{
Corresponding Author:

Milena Sia Perin

Rua Rui Barbosa, 887

Centro

CEP 13160-000, Artur Nogueira, SP, Brasil

E-mail: misperin@gmail.com
} 


\section{Introduction}

Studies indicate that approximately 16.7 million individuals worldwide die each year from cardiovascular disease, with approximately eight million deaths attributed to hypertension $(\mathrm{SAH})^{(1)}$. Among the factors related to the development and progression of hypertension, the elevated consumption of salt has been directly associated with the increase in blood pressure levels and the occurrence of cardiovascular complications ${ }^{(2-7)}$. Although there are international and Brazilian recommendations for the limiting of sodium consumption both for the population in general and for hypertensive individuals of $5 \mathrm{~g}$ and $4 \mathrm{~g}$ respectively ${ }^{(8-9)}$, studies with different populations show a consumption of sodium which is higher than the recommended ${ }^{(9-14)}$, with an average of up to $4600 \mathrm{mg}$ of sodium ( $11.5 \mathrm{~g}$ of salt)/day ${ }^{(7)}$.

An important study in the area, the INTERSALT ${ }^{(2-3)}$, undertaken with 10,079 men and women between 20 and 59 years of age, from 52 centers, aimed at testing hypotheses within and between populations regarding the relationship between 24-hr urinary sodium excretion and levels of blood pressure. The study ratified that the high consumption of salt is a world-wide phenomenon, not being restricted to specific groups. It was also evidenced that, with the exception of four centers in which sodium consumption was effectively very low, the urinary excretion was related to the increase in blood pressure.

Sodium intake, however, is the result of varying nutritional behaviors, resulting from the different sources of consumption of the nutrient. A study undertaken with hypertensive patients being monitored in a university hospital outpatient center in the interior of the state of São Paulo showed that the patients added around $7.2 \mathrm{~g}$ of salt to foods (during or after their preparation), in addition to frequently consuming foods with high salt content, such as pre-packaged seasonings and meat stocks, which are rich in sodium and are heavily-used in the preparation of foods. In adding the salt which is added in the preparation of foods to the sodium already present in the foods in natura (identified by the 24hr dietary recall) and in high salt content foods, the daily consumption increased to $13.5 \mathrm{~g}$ of salt(13). The contribution of each source of consumption of sodium can vary, however, according to social groups, culture, and eating habits and practices.

In the United Kingdom, in a study carried out with 23,104 subjects from the community aged between 45 and 79 years old, it was observed that salt consumption was greater among men than among women ${ }^{(10)}$. Another study compared the salt intake among non-hypertensives and hypertensives, with greater salt consumption being observed in the latter group ${ }^{(14)}$. The authors therefore researched socio-demographic and clinical differences between hypertensives and non-hypertensives. It was identified that the individuals with hypertension were older, had a lower level of education, were less active physically, had a greater frequency of previous history of smoking, and higher BMI than the non-hypertensives. In this study, however, the association between the sociodemographic variables and salt consumption per se was not analyzed.

With a view to the planning and implementation of educational strategies for reducing salt intake among hypertensives, a previous study ${ }^{(12,15)}$ had investigated the psychosocial determinants related to the consumption of sodium in these individuals. Three behaviors related to salt consumption were evaluated: the addition of, at the most, $4 \mathrm{~g}$ of salt in the preparation of meals (Behavior I); avoiding adding salt to already-prepared foods, as well as avoiding using a salt cellar at the table (Behavior II) and avoiding consuming foods with high salt content (Behavior III). It was observed that each behavior was determined by distinct psychosocial variables, indicating the need to plan interventions specific to each one of the behaviors investigated. In this study, however, the association between socio-demographic and clinical variables and salt consumption was not researched. Considering the importance of the variation of this nutritional behavior according to individual socio-demographic and clinical characteristics, the present study was aimed at evaluating the association between the behaviors related to salt intake and socio-demographic and clinical variables, with a purpose of identifying possible patterns of consumption according to individual characteristics.

\section{Method}

The present study is a cross-section from a broader, longitudinal study, which investigated the psychosocial determinants of sodium consumption among hypertensive patients(12), according to the behaviors: $\mathrm{I}$ - addition of a maximum of $4 \mathrm{~g}$ of salt in the preparation of meals; II - avoiding adding salt to foods already prepared, as well as the use of a salt at the table; and III - avoiding consuming foods with high sodium content.

\section{Subjects}

The study included 108 patients diagnosed with hypertension, in regular attendance at the outpatient 
center specialized in cardiology of a university hospital in the interior of the state of São Paulo, who had been in follow-up for hypertension receiving treatment on an outpatient basis for at least six months. Subjects were excluded if they were unable to communicate effectively orally. For behavior I, an additional inclusion criteria was used: only women responsible for the preparation of their meals, to avoid gender bias (due to the small number of men who cook their own meals). At the end, the study enrolled 108 subjects of both sexes for behaviors II and III. Among these, 52 women were also included for the studying of behavior I.

\section{Data collection}

Data assessment was done at the first contact with the patient in the above-mentioned outpatient center, prior to the medical consultation. Firstly, the patient was informed about the research's objectives; shortly after, the consent document was signed, and data regarding socio-demographic and clinical characterization and salt intake. In the week following the first interview, the patient returned with the 24-hr urine collection, for analysis of the urinary sodium excretion ${ }^{(12)}$.

For the 24-hour urine collection, the patient was advised to start the collection on the day prior to the delivery of the urine, disregarding all of the first urine, on waking up in the morning. Thus, from the second urine of the day onward, all the urine should be collected in the container provided until the first urine of the following morning. It was recommended keeping the container in a fresh and well-aired place.

\section{Instruments}

The instruments used for the socio-demographic and clinical characterization and for the measurements of the behaviors of salt consumption had previously been validated(15).

\section{Socio-demographic and clinical characterization}

The following data was obtained: age, sex, color, schooling, marital situation, employment situation, individual and family monthly income; length time of the hypertension diagnosis; medications in use; echocardiographic data (left ventricular mass ratio/ body surface area, in $\mathrm{g} / \mathrm{m}^{2}$; measurements of the interventricular septum and the left ventricle's posterior wall, in millimeters; these obtained from the patient's medical records), blood pressure (with a digital device certified by the American Heart Association, with the patient seated with the arms supported at the level of the heart); body weight (in kilograms) and height (in meters) (obtained with the patient wearing a minimum of clothes and without shoes, on weighing scales). The Body Mass Index (BMI) was estimated using the formula: weight/height ${ }^{2}$ (12).

Self-evaluation of the behaviors related to salt consumption

The three behaviors related to salt consumption were measured with the questions described below, with the option to respond using a five-point scale: (1) every day of the week; (2) most days of the week; (3) sometimes; (4) rarely; (5) never. The higher the score, the less the healthy behavior was undertaken, and, therefore, the greater the salt intake(15).

- Behavior I: "In the last 2 months, what best describes your behavior of using a maximum of $4 \mathrm{~g}$ of salt per day in preparing your meals - that is, one tea-spoon of salt per day for the preparation of all the meals (breakfast, lunch, dinner and snacks)?"

- Behavior II: "In the last 2 months, what best describes your behavior of avoiding adding salt to alreadyprepared foods (on the plate) as well as avoiding the use of a salt cellar at the table?"

- Behavior III: "In the last 2 months, what best describes your behavior of avoiding consuming foods with high salt content, such as industrialized foods, cold meats, canned foods and ready-made sauces?"

Objective measurements of salt consumption

Discretionary salt: a questionnaire aimed at quantifying the household's salt consumption, constituted of the questions: "How many packets of salt get used in your house every month?" "How many people have lunch and dinner in your house per week (with discrimination of age and how many meals each individual has per week)"? The resulting value was adjusted to the quantity of grams of salt consumed by the subject per day.

24-hr dietary recall: an instrument made up of seven items, each related to one meal (Breakfast; Morning snack; Lunch; Afternoon snack; Dinner; Supper; night-time snacks), so as to quantify the sodium present in natura in the foods. The dietary recall encompasses the recording by the researcher of all the food consumed by the patient in the 24 hours prior to the interview. The final amount of sodium given by the dietary recall is the result of the sum of the sodium present in each of the foods consumed on the previous day. The result obtained 
was transformed into grams of salt, considering that $1 \mathrm{~g}$ of salt $=400 \mathrm{mg}$ of sodium .

Sodium - Food frequency questionnaire (Na-FFQ): this instrument evaluates the consumption of foods with high sodium content ${ }^{(13)}$. The Na-FFQ is constituted by 15 foods, in relation to which the patient reports the frequency of consumption of each one, on a seven-point scale: (1) never; (2) less than once a month; (3) one to three times a month; (4) two to four times a week; (5) once a day; (6) once a week; (7) twice or more per day. The interviewee must also identify the portion consumed (small, medium or large), using as a reference the quantity referent to the average portion of each one of the items. The result, obtained in milligrams of sodium, was converted to grams of salt.

Total salt intake: the sum of the salt consumption obtained by the measurements of discretionary salt, the 24-hr dietary recall and the Na-FFQ.

24-hr urinary sodium excretion (NaUri): the quantification of the urinary excretion of sodium over the 24 hour period was undertaken in accordance with the standard procedure of the clinical pathology laboratory of the health institution in the study, which uses the atomic absorption spectroscopy method(16). The 24-hour urinary excretion of sodium is a biological marker, considered the gold standard for the quantification of daily sodium consumption, as approximately $86 \%$ of the sodium excreted in the urine comes from the salt consumed.

\section{Data analysis and Ethical aspects}

The SPSS software (Statistical Package for the Social Sciences), version 16.0 was used for the following analyses: descriptive, of correlation (Spearman), association (Pearson's Chi-squared) and of comparison (Mann-Whitney). For the analyses of association and comparison, the objective and subjective variables of the behaviors related to salt consumption were transformed into categorical variables: low consumption (25 th $q u a r t i l e)$ and high consumption ( $75^{\text {th }}$ quartile). The $p$-value of $<0.05$ was adopted as statistically significant. Both the original project and this cross-sectional analysis were approved by the local Ethics Committee under N563/2006 and approved in the X Regular Meeting of the CEP/FCM, on October $27^{\text {th }} 2009$.

\section{Results}

Table 1 presents the description and sociodemographic and clinical characterization of the measurements of the salt consumption behaviors.

The self-evaluation measurements have average scores of between 2.7 and 4.9. Higher scoring was observed for Behavior II - which showed little variability between the interviewees $($ mean $=1.1$; median $=1.0$ and IQR = 0), which means that the majority of the subjects interviewed referred to not adding salt to already-prepared meals, and to not having a salt cellar at the table. Behaviors I and III, however, have higher means and greater variability in the group studied.

The analysis of the specific measurements of sodium consumption indicated a mean urinary sodium excretion of $209.3 \mathrm{mEq} / 24 \mathrm{~h}$, which corresponds to a mean daily consumption of $12.1 \mathrm{~g}$ of salt(17). The mean use of discretionary salt was $7.5 \mathrm{~g}$ per day, a quantity significantly greater than the daily salt consumption identified both by the 24-hr dietary recall, which was $2.1 \mathrm{~g}$, and by the food frequency questionnaire for sodium - FFQSo, which was $2.5 \mathrm{~g}$. The total daily salt intake (the sum of discretionary salt, 24- hr dietary recall and the $\mathrm{Na}-\mathrm{FFQ}$ ) was $12.2 \mathrm{~g}$ (Table 1 ).

Table 1 - Socio-demographic and clinical characterization, and of salt intake $(n=108)$. Campinas, São Paulo, Brazil, 2007-2008

\begin{tabular}{|c|c|c|c|}
\hline & Mean (sd) & Median $\left(\mathrm{IQR}^{\star}\right)$ & $n(\%)$ \\
\hline \multicolumn{4}{|l|}{ Socio-demographic variables } \\
\hline Sex (female) & & & $56(51.9 \%)$ \\
\hline Age (years) & $56.7(8.7)$ & $56,0(11.0)$ & \\
\hline Color (white) & & & $65(60.2 \%)$ \\
\hline Marital situation (with partner) & & & $82(75.9 \%)$ \\
\hline Schooling (years) & $6.7(4.0)$ & $5.0(4.0)$ & \\
\hline Employment situation (inactive) & & & $59(54.6 \%)$ \\
\hline Individual income $(\mathrm{MS})^{\dagger}$ & $2.3(1.9)$ & $2.0(2.1)$ & \\
\hline Family income $(\mathrm{MS})^{\dagger}$ & $4.1(30)$ & $3.4(2.9)$ & \\
\hline
\end{tabular}


Table 1 - (continuation)

\begin{tabular}{|c|c|c|c|}
\hline & Mean (sd) & Median (IQR*) & $n(\%)$ \\
\hline \multicolumn{4}{|l|}{ Clinical variables } \\
\hline Duration of hypertension (years) & $14.2(10.0)$ & $11.5(13.8)$ & \\
\hline Systolic arterial pressure $(\mathrm{mmHg})$ & $150.3(29.2)$ & $146.5(34.7)$ & \\
\hline Diastolic arterial pressure $(\mathrm{mmHg})$ & $88.0(15.5)$ & $86.0(16.0)$ & \\
\hline Mean Blood pressure $(\mathrm{mmHg})$ & $108.7(18.7)$ & $105.8(19.5)$ & \\
\hline Number of medications & $3.0(1.0)$ & $3.0(2.0)$ & \\
\hline Mass ratio / Body surface area $\left(\mathrm{g} / \mathrm{m}^{2}\right)$ & $148.0(47.2)$ & $140.0(41.0)$ & \\
\hline Septum (mm) & $10.9(1.9)$ & $11.0(2.0)$ & \\
\hline Left ventricle posterior wall (mm) & $10.7(1.5)$ & $11.0(2.0)$ & \\
\hline Weight & $81.7(17.1)$ & $80.5(24.0)$ & \\
\hline Height & $1.60(0.09)$ & $1.58(0.14)$ & \\
\hline Body mass index $\left(\mathrm{kg} / \mathrm{m}^{2}\right)$ & $32.0(6.3)$ & $31.4(8.6)$ & \\
\hline \multicolumn{4}{|l|}{ Salt consumption } \\
\hline \multicolumn{4}{|l|}{ Subjective measurement } \\
\hline Behavior I & $3.25(1.76)$ & $4.0(4.0)$ & \\
\hline Behavior II & $1.13(0.56)$ & $1.0(0)$ & \\
\hline Behavior III & $3.12(1.23)$ & $3.0(2.0)$ & \\
\hline \multicolumn{4}{|l|}{ Objective measurements } \\
\hline 24-hr urinary $\mathrm{Na}$ excretion $-(\mathrm{mEq} / 24 \mathrm{~h})(\mathrm{n}=100)$ & $209.3(100.0)$ & $202.0(132.6)$ & \\
\hline Discretionary Salt (g salt/day/person) $(n=107)$ & $7.5(4.4)$ & $6.3(4.4)$ & \\
\hline 24-hr Dietary recall (g salt/day) $(n=108)$ & $2.1(1.3)$ & $1.9(1.4)$ & \\
\hline Sodium-Food frequency questionnaire ( $g$ salt/day) $(n=108)$ & $2.5(2.7)$ & $1.7(2.7)$ & \\
\hline $\begin{array}{l}\text { Total salt intake }(24-\mathrm{hr} \text { dietary recall }+ \text { discretionary salt }+ \\
\text { sodium-food frequency questionnaire ) ( } g \text { salt/day) }(n=108)\end{array}$ & $12.2(5.8)$ & $11.1(6.8)$ & \\
\hline
\end{tabular}

*IQR: inter-quartile range (Q3-Q1); † Minimum Salary $=\mathrm{R} \$ 380.00$

The correlation analyses are presented in Table 2. Distinct patterns of correlation may be observed between the different behaviors of sodium intake and the socio-demographic and clinical variables. Behavior I correlated negatively with the variables: schooling, systolic blood pressure and number of medications. For Behavior III, the following correlations were highlighted: with diastolic blood pressure and with the ratio left ventricular mass /body surface area. In relation to the NaUri, it was observed that it correlated with monthly individual income, BMI and left ventricular mass. Both the measurement of the Na-FFQ and the estimate of total salt intake are correlated significantly only with the BMI.

For the analyses of association and comparison, the variables referent to sodium intake were considered as categorical (low or high consumption) according to the $25^{\text {th }}$ and $75^{\text {th }}$ percentiles (P25 and P75). The results of the analyses of association are presented in the form of charts, in Figure 1.

Table 2 - Correlations (Spearman) followed by the $p$-value between the different measurements of salt consumption and socio-demographic and clinical variables. $(n=108)$. Campinas, São Paulo, Brazil, 2007-2008

\begin{tabular}{|c|c|c|c|c|c|}
\hline & Behavior I & Behavior III & $\begin{array}{l}24 \text { hour urinary } \\
\text { sodium }\end{array}$ & $\begin{array}{l}\text { Food frequency } \\
\text { questionnaire for } \\
\text { sodium }\end{array}$ & Total salt \\
\hline Schooling & $-0.31(0.027)$ & not significant & not significant & not significant & not significant \\
\hline Individual monthly income & not significant & not significant & $0.250(0.012)$ & not significant & not significant \\
\hline Systolic Blood pressure & $-0.316(0.022)$ & not significant & not significant & not significant & not significant \\
\hline Diastolic Blood Pressure & not significant & $0.218(0.024)$ & not significant & not significant & not significant \\
\hline Number of medications & $-0.309(0.026)$ & not significant & not significant & not significant & not significant \\
\hline Body Mass Index & not significant & not significant & $0.289(0.004)$ & $0.232(0.016)$ & $0.309(0.001)$ \\
\hline Ventricular mass & not significant & not significant & $0.313(0.002)$ & not significant & not significant \\
\hline $\begin{array}{l}\text { Ventricular mass/Body surface } \\
\text { area }\end{array}$ & not significant & $-0.297(0.002)$ & not significant & not significant & not significant \\
\hline
\end{tabular}



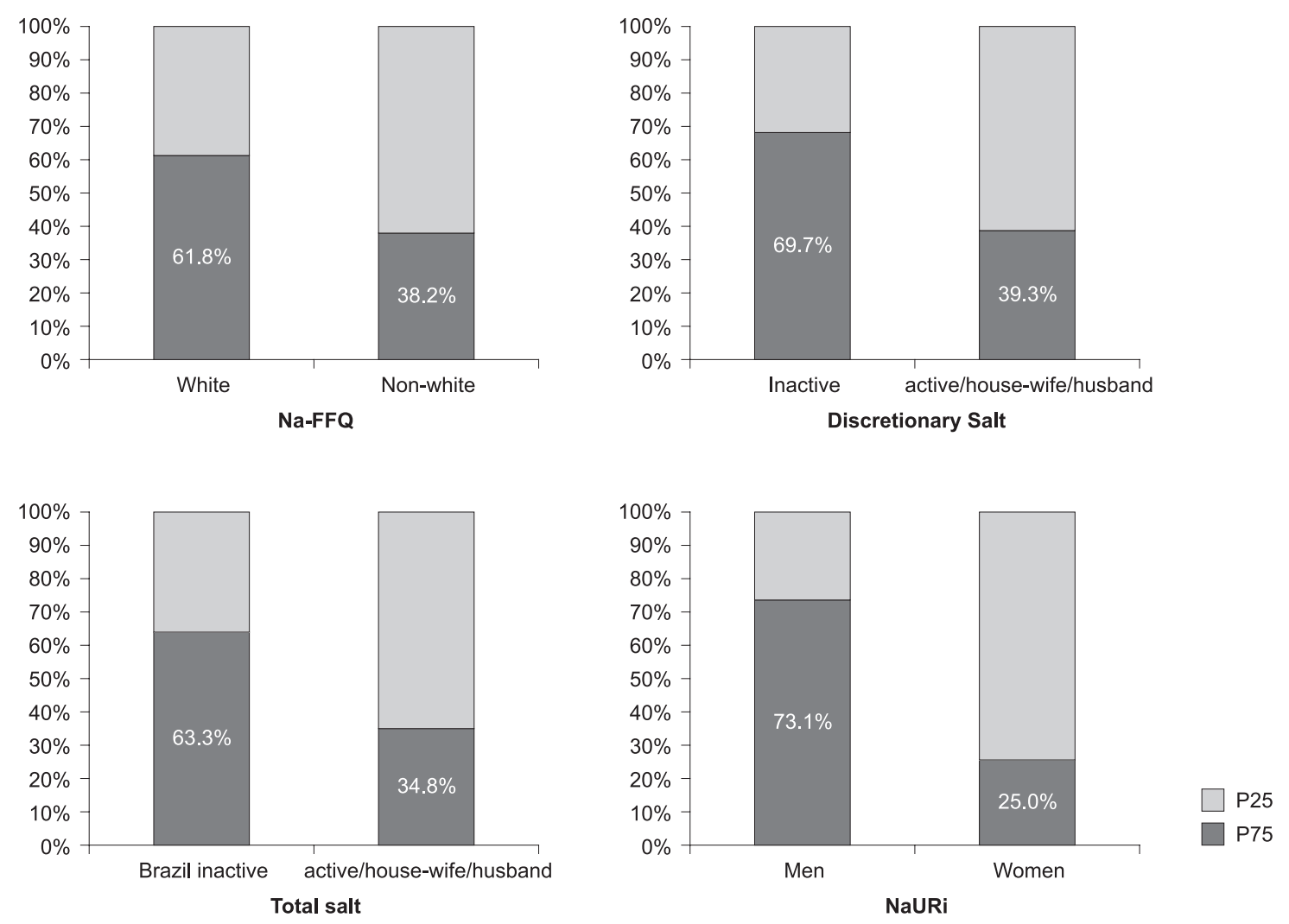

Figure 1 - Proportions of distribution of the study's subjects according to extremes of consumption (25 th and $75^{\text {th }}$ percentiles), and socio-demographic variables (color, professional activity and sex). Campinas, São Paulo, Brazil (2007-2008).

For the analyses of comparison, the variables referent to sodium intake were also considered as categorical, according to the $25^{\text {th }}$ and $75^{\text {th }}$ percentiles. Subjects with a greater salt consumption quantified by the Na-FFQ were heavier than those with lesser consumption $(84.6 \times 73.3 \mathrm{Kg} ; \mathrm{p}=0.009)$. In relation to BMI, subjects with greater discretionary salt intake had higher BMI when compared to subjects with lesser consumption $\left(32.5 \times 28.9 \mathrm{Kg} / \mathrm{m}^{2} ; \mathrm{p}=0.013\right)$. The patients with greater total salt consumption had a higher BMI than those subjects with a lower total salt consumption (32.6 $628.9 \mathrm{Kg} / \mathrm{m}^{2} ; \quad \mathrm{p}=0.007$ ). Regarding the measurement of NaUri, patients with greater urinary excretion of sodium had a higher income than those with lowerexcretion ( $3.1 \times 1.7 ; \mathrm{p}=0.039)$; aswellasahigherBMI $\left(34.1 \mathrm{Kg} / \mathrm{m}^{2} \times 28.8 \mathrm{Kg} / \mathrm{m}^{2} ; \mathrm{p}=0.001\right)$.

\section{Discussion}

This study's sample was characterized by a moderately elevated age, a slight predominance of females, whites, low schooling and low monthly income, all of which have been observed in studies undertaken with populations attended by the Brazilian Unified Health System ${ }^{(18)}$. Studies have indicated being female, having a low income and low schooling as poor prognostic factors for cardiovascular morbi-mortality ${ }^{(19)}$, which suggests the vulnerability of the group studied for cardiovascular events.

Regarding the clinical characterization, the study's subjects are already in a chronic condition, with a mean length time of their hypertension diagnosis of 14 years, supposing the patient to have been clarified as to the disease and there to have been stable clinical treatment. However, even with the use of approximately three classes of anti-hypertensive medication, the blood pressure levels observed indicate dissatisfactory control of arterial pressure. The high levels of systolic pressure $(150.3 \mathrm{mmHg})$ are highlighted, which in their turn are associated with a progressive increase in cardiovascular risk $^{(8)}$. The consequences of high pressure levels are evidenced by the confirmation of ventricular hypertrophy, as denoted by the high values of the mass/left ventricle and of the borderline values of the interventricular septum and the posterior wall of the left ventricle. 
Also highlighted is the presence of the condition of obesity or overweight, with mean BMI values of around $32.0 \mathrm{~kg} / \mathrm{m}^{2}$, classified as Grade I obesity. Obesity is a clinical condition of growing prevalence, reaching epidemic proportions worldwide. Adiposity, or excess of body fat, is associated with increase in morbidity, incapacity and premature death from cardiovascular diseases and other clinical conditions ${ }^{(20)}$. The relationship between obesity and blood pressure levels was clinically demonstrated in the Framingham study in the 1960's. Later, clinical and experimental studies validated the relationship between obesity and arterial hypertension, and the confirmation that the combined presence of the two conditions increases the cardiovascular risk significantly(21), in addition to making the hypertension treatment even more complex.

Thus, the socio-demographic and clinical characterization of the subjects studied points to a significant vulnerability to cardiovascular events, which requires of the health team directive clinical interventions aimed at promoting the adoption of a healthy lifestyle, optimization of the pharmacological treatment, and the encouragement to comply with pharmacological and non-pharmacological treatment.

Regarding nutritional behavior, the data points to the urgent need for change in the pattern of salt consumption, as the specific measurements of consumption, when added together, reveal a consumption which is three times that recommended for this population. The separate analysis of the specific measurements indicates discretionary salt as the main source of salt consumption, representing approximately $62 \%$ of the total salt consumed. Also from the subjective measurements, one can learn that the most frequent behavior is the use of salt in the preparation of the foods (Behavior I) and what is reported regarding the use of discretionary salt. Behavior II, which refers to the use of the salt at the table and to the salt added to the foods already prepared, showed low scoring and very little variation, which means that in the group studied the great majority, if not all the participants, neither used the salt at the table, nor had the habit of adding salt to the foods after their preparation. This observation explains the exclusion of Behavior II in the inferential analyses. The data indicates the relevancy of the behavior of adding salt in food preparation in the nurse's planning of educational interventions, with a view to helping the patients reduce salt consumption (22).

The analyses which tested the association between salt consumption and the socio-demographic and clinical variables indicated different patterns of association, depending on the measurement used to evaluate the consumption of this nutrient.

In relation to the economic factors, the individual and family monthly income were positively related to the sodium intake, as given by the urinary excretion of sodium. This is interesting data, particularly considering that the population studied was characterized by a low family income, with a median of two minimum salaries. It is possible that small increases in their acquisitive power permit them greater access to industrialized foods with higher salt content, thus contributing to a higher final consumption of the nutrient. Advice on recognizing processed foods' salt content through reading the nutritional information contained on these foods' labels is fundamental to help the patient make healthier choices among food products.

Schooling was negatively correlated with Behavior I that is, as the level of schooling rises, less salt is added by the women (behavior studied exclusively among women who cook), in the preparation of the foods. In this way, special attention and specific interventions must be outlined for the women with lower levels of schooling, with a view to reducing the quantity of salt used in preparing their meals.

In their turn, the association analyses, considering the extremes of consumption, given by the different measurements showed a relationship between the pattern of salt consumption and variables such as sex, color and professional situation. It is more frequent for men to have a higher level of salt consumption than the women, given by the criteria of urinary sodium, which may be associated with a higher taste threshold for the detection and recognition of salt for men than for women. The data in the present study reproduces what has been found on a worldwide scale ${ }^{(23)}$.

It was also observed that white patients consume foods with high sodium content more frequently than do non-white patients. Furthermore, professionallyinactive individuals present a higher proportion of high salt consumption - given both by the measurement of discretionary salt intake and by the sum of the measurements of salt intake - than those who are professionally active or who are house-wives/husbands. A recent study undertaken with a sample of university students in Malaysia investigated the per capita preference and consumption of foods with high salt content by ethnic origin, blood pressure levels, and anthropometric measurements(24). Differences were observed in the preference and in the consumption 
of foods with high salt content and discretionary salt between the two ethnicities studied (Chinese and Indian). Future studies must explore the possible cultural and contextual influences on these patterns of behavior. The social influence on the foods' flavors can exercise a significant role in the choices made regarding the seasoning of the meals, making it difficult for the hypertensive to reduce salt consumption.

Among the clinical variables, BMI stands out, a variable which showed associations with practically all the measurements of salt consumption (urinary sodium, NaFFQ and total salt intake): the greater the BMI, the greater the consumption. The excessive consumption of salt among obese people may be explained by their greater consumption of calories, if one considered principally that many high-calorie processed foods have a high sodium content used as a preservative. In addition to this, in preparing foods, those with a higher fat content - and therefore more calories - may require a greater quantity of salt to satisfy the palate. It is possible, however, that these explanations may not be exhaustive.

The most in-depth study on the causes of the greater consumption of salt among the obese is of extreme relevance, in the face of what has been described as the result of experimental and clinical studies. The literature indicates a consensus that high salt consumption in the presence of dysfunctional adipose tissue is implicated in the mechanism of insulin resistance, an element which triggers the metabolic changes caused by obesity(25). Thus, it is necessary for the nurse to investigate, with special attention, salt consumption among individuals whose BMI is above normal values, as the high salt consumption in this group of hypertensives can have even more serious consequences.

The analyses further emphasize what is being described in relation to sodium consumption and the clinical progression of hypertension. Positive correlations were confirmed between the left ventricular mass ratio and urinary sodium and between diastolic blood pressure and Behavior III, in that the greater the urinary sodium, the greater the ventricular mass, and the more the patient reports consuming foods with high salt content, the greater the diastolic blood pressure.

It is interesting to note the correlation observed between Behavior I and the variables 'number of medications' and 'systolic blood pressure': the greater the number of medications used and the higher the systolic blood pressure (two immediate indicators to the patient of the gravity of his illness), the more the women report restricting the addition of salt in the preparation of the foods. Thus, in this case, perhaps the perception of the risk or of the severity of the illness may contribute positively to the adoption of the hoped-for behavior, and should be taken into account in the nurse's planning of educational activities.

\section{Final Considerations}

The results indicate that the high consumption of salt, whether measured by its components in isolation or globally, is related to individual variables such as sex, schooling, color, monthly income and professional situation, and to clinical variables such as BMI, arterial pressure, indicators of ventricular hypertrophy and the number of medications used. Educational interventions must be specifically directed at changing different behaviors related to salt consumption, and aimed principally at individuals who are male, white, with low levels of schooling, higher monthly incomes and who are professionally inactive. Moreover, special attention must be given to subjects who are overweight/obese, who can benefit substantially from reducing salt consumption. On the other hand, the recognition of the risk or of the seriousness of the illness, given by the number of classes of anti-hypertensive drugs used, and by the level of the systolic blood pressure, can be used as an educational tool to assist in the adoption of healthier behavior in relation to salt consumption.

\section{References}

1. Havas S, Rocella EJ, Lenfant C. Reducing the public health burden from elevated blood pressure levels in the United States by lowering of dietary sodium. Am J Public Health. 2004;94(1):19-22.

2. Stamler J. The INTERSALT study: Background, methods, findings and implications. Am J Clin Nutr. 1997;65(Suppl):626S-42S.

3. Elliott $P$, Stamler J, Nichols R, Dyer AR, Stamler R, Kesteloot $H$, Marmot $M$. Intersalt revisited: further analyses of 24 hour sodium excretion and blood pressure within and across populations. Intersalt Cooperative Research Group. BMJ. 1996;312(7041):1249-53.

4. He FJ, MacGregor GA. Salt intake, plasma sodium, and worldwide salt reduction. Ann Med. 2012;44(Suppl 1):S127-S147.

5. Khosravi A, Kelishadi R, Sarrafzadegan N, Boshtam M, Nouri F, Zarfeshani S, et al. Impact of a communitybased lifestyle intervention program on blood pressure and salt intake of normotensive adult population in a developing country. J Res Med Sci. 2012;17(3):235-41. 
6. Cappuccio FP, Kerry SM, Micah FB, Plange-Rhule J, Eastwood JB. A community programme to reduce salt intake and blood pressure in Ghana. BMC Public Health. 2006;6:13.

7. Brown IJ, Tzoulaki I, Candeias V, Elliott P. Salt intakes around the world: implications for public health. Int J Epidemiol. 2009;1-23.

8. Sociedade Brasileira de Hipertensão, Sociedade Brasileira de Cardiologia e Sociedade Brasileira de Nefrologia. VI Diretrizes Brasileiras de Hipertensão Arterial [Internet], 2010 [acesso 26 dez 2012]. Disponível em: http://publicacoes.cardiol.br/consenso/2010/Diretriz _hipertensao_associados.pdf

9. US Department of Agriculture, Agricultural Research Service. What we eat in America. [Internet], 2011 [acesso 29 dez 2012]. Disponível em: http://www.ars. usda.gov/services/docs. htm?docid $=15044$.

10. Khaw KT, Bingham S, Welch A, Luben R, O'Brien E, Wareham $N$, et al. Blood pressure and urinary sodium in men and women: the Norfolk Cohort of the European Prospective Investigation into Cancer (EPIC - Norfolk). Am J Clin Nutr. 2004;80:1397-403.

11. Ueshima $\mathrm{H}$, Zhang X-H, SR Choudhury. Epidemiology of hypertension in China and Japan. J Hum Hypertension. 2000;14:765-9.

12. Cornélio ME, Gallani MC, Godin G, Rodrigues RC, Nadruz W Jr, Mendez RD. Behavioural determinants of salt consumption among hypertensive individuals. J Hum Nutr Diet. 2012;25(4):334-44.

13. Ferreira-Sae MC, Gallani MC, Nadruz W, Rodrigues RC, Franchini KG, Cabral PC, et al. Reliability and validity of a semi-quantitative FFQ for sodium intake in lowincome and low-literacy Brazilian hypertensive subjects. Public Health Nutr. 2009;28:1-6.

14. Ajani UA, Dunbar SB, Ford ES, Mokdad $A H_{\text {, }}$ Mensah GA. Sodium intake among people with normal and high blood pressure. Am J Prev Med. 2005; 29(5S1):63-7.

15. Cornélio ME, Gallani MCBJ, Godin G, Rodrigues RC, Mendez RDR, Nadruz Junior W. Development and reliability of an instrument to measure psychosocial determinants of salt consumption among hypertensive patients. Rev. Latino-Am. Enfermagem. 2009; 17(5):701-7.

16. Molina MCB, Cunha RS, Herkenhoff LF, Mill JG. Hipertensão arterial e consumo de sal em população urbana. Rev Saúde Pública. 2003;37(6):743-50.

17. He FJ, MacGregor GA. Reducing population salt intake worldwide: from evidence to implementation. Prog Cardiovasc Dis. 2010;52(5):363-82.
18. Piovesana PM, Colombo RCR, Gallani MCBJ. Hypertensive patients and risk factors related to physical activity and nutrition. Rev Gaúcha Enferm. dez 2006;27(4):557-63.

19. Swahn E. The care of patients with ischaemic heart disease from a gender perspective. Eur Heart $\mathrm{J}$. 1998; 19:1758-65.

20. Nguyen T, Lau DC. The obesity epidemic and its impact on hypertension. Can J Cardiol. 2012;28(3):326-33

21. Landsberg L, Aronne LJ, Beilin LJ, Burke V, Igel LI, Lloyd-Jones D, Sowers J. Obesity-related hypertension: pathogenesis, cardiovascular risk, and treatment: a position paper of the obesity society and the american society of hypertension. J Clin Hypertens (Greenwich). 2013;15(1):14-33

22. Agondi RF, Gallani MCBJ, Cornelio ME, Rodrigues RCM. Analysis of action plans and coping plans for reducing salt consumption among women with hypertension. Rev. Latino-Am. Enfermagem. 2012;20(3):486-94.

23. Elliott $P$, Brown I. Sodium intakes around the world. Geneva: World Health Organization; 2007.

24. Choong SS, Balan SN, Chua LS, Say YH. Preference and intake frequency of high sodium foods and dishes and their correlations with anthropometric measurements among Malaysian subjects. Nutr Res Pract. 2012;6(3):238-45.

25. Lastra G, Dhuper S, Johnson MS, Sowers JR Salt, aldosterone, and insulin resistance: impact on the cardiovascular system. Nat Rev Cardiol. 2010;7(10):577-84. 